\title{
Obituary: Michael Dopita, Former Editor in Chief of Astrophysics and Space Science
}

\author{
Elias Brinks ${ }^{1} \cdot$ Jeremy Mould ${ }^{2} \cdot$ Ramon Khanna $^{3}$
}

Published online: 16 January 2019

(c) Springer Nature B.V. 2019

It is with great sadness we learned about the passing of our colleague, and former Editor of this journal, Professor Michael Dopita.

Michael Dopita is remembered as one of the foremost authorities in atomic and interstellar astrophysics. His range of achievements in theoretical astrophysics and ground-based and space observational astrophysics was extraordinarily broad. He made fundamental contributions to research on astrophysical plasma diagnostics, star formation in galaxies, the physics of planetary nebulae, supernova remnants, active galactic nuclei and radio jets. He advised and mentored many graduate students in a most generous and supportive way. He was a major user of the Hubble Space Telescope, scientifically supporting the design of its final camera, and later extending his design talents to a superb Integral Field Spectrograph for the Australian National University's Siding Spring Observatory.

At ApSS we remember Mike for his outstandingly successful editorship from 2006 to 2014, raising the standing of the journal significantly, thereby supporting the careers of many in the community and advancing our knowledge of astrophysics. He will be greatly missed by many friends, colleagues, former students, colleagues and the au-

\footnotetext{
$\triangle$ E. Brinks

e.brinks@herts.ac.uk

J. Mould

jmould@swin.edu.au

R. Khanna

ramon.khanna@springer.com

1 University of Hertfordshire, College Lane, Hatfield, AL10 9AB, UK

2 Swinburne University of Technology, PO Box 218, Hawthorn, Vic 3122, Australia

3 Springer, https://www.springer.com
}

thors whose papers he read, appreciated, and promoted as Editor in Chief.

Mike not only served as Editor in Chief of Astrophysics and Space Science but also for many years as one of the Series Editors of the Springer book series Astronomy and Astrophysics Library where his scientific and editorial input was much appreciated and where he helped judge and improve several books.

Mike was a Fellow of the Australian Academy of Science and Treasurer for 6 years. In this capacity he contributed to the advancement of science across all disciplines.

On behalf of all Editors, Associate Editors, and Editorial and Advisory Board Members who had the privilege to work with or know Mike Dopita,

Jeremy Mould and Elias Brinks

Editors-in-Chief

\section{Ramon Khanna}

Executive Editor Astronomy, Springer

Publisher's Note Springer Nature remains neutral with regard to jurisdictional claims in published maps and institutional affiliations. 